\title{
Utkantmedisin i Nepal
}

\author{
De siste sju årene har jeg vært eneste overlege ved Okhaldhunga sykehus, som betjener vel 200000 \\ mennesker. Medisinske assistenter behandler de fleste pasientene som kommer til poliklinikken. \\ Nærmeste aktuelle henvisningssted er hovedstaden Katmandu - to lange dagers kjøring unna og \\ med usikker veiforbindelse.
}

\section{Erik Bøhler}

bohler@wlink.com.np

Okhaldhunga Community Hospital

United Mission to Nepal

Box 126 Kathmandu

Nepal

Å arbeide som lege i Nepal er på mange måter forskjellig fra i Norge. Det er gjennomsnittlig to leger per 10000 innbyggere, mens det tilsvarende tallet i Norge er 38 per 10000 innbyggere. I tillegg er dødeligheten høyere for både barn og voksne i Nepal (1).

Min bakgrunn som norsk barnelege er klart utilstrekkelig her. Men i denne arbeidssituasjonen ville knapt noen utdanningsbakgrunn føles tilstrekkelig, og med tiden samler man nyttig erfaring. Hvis ikke dette sykehuset hadde fungert, ville befolkningen i distriktet ha stått uten viktige helsetjenester. Det er en stor motivasjonsfaktor. Til nå har det vært umulig å rekruttere nepalske leger med spesialistbakgrunn til å jobbe her permanent, mye fordi sykehuset ligger på landsbygda i et område med dårlig tilgang på moderne fasiliteter (fig 1).

\section{Uforutsigbar bemanning}

Okhaldhunga Community Hospital er det eneste sykehuset i Okhaldhunga-distriktet, som har en befolkning på vel 200000 mennesker. Til sammenlikning betjener f.eks. Sykehuset Asker og Bærum en befolkning på 149000 (2). Sykehuset drives av den internasjonale misjonsorganisasjonen United Mission to Nepal. Det har offisielt bare 32 senger, men antall innlagte er nesten alltid høyere enn dette, og en utbygging planlegges. Legestaben består av én fast ansatt (undertegnede) og 1-3 leger i spesialisering. Disse er i ferd med å spesialisere seg $\mathrm{i}$ «general practice», tilknyttet et av de tre universitetene $i$ landet som gir slik spesialistutdanning. Den er ment å sette dem i stand til selv å lede et distriktssykehus. Utdanningen er treårig, og seks måneder av det siste året skal de arbeide ved et distriktssykehus. For at dette skal bli godkjent av universitetene kreves en fast ansatt overlege. Dem er det ikke så mange å velge blant i landet, så vi får mange slike kandidater til Okhaldhunga. Dette gir sykehuset en sentral plass i utdanningen av en viktig gruppe leger, og oppleves både som en tillitserklæring og en stor utfordring.

Flere av dem har kommet tilbake for å jobbe her etter endt spesialisering, men bare for noen måneder. Vi håper å kunne rekruttere slike leger til å arbeide her fast, ettersom antallet av denne typen spesialister øker. Det vil kunne avhjelpe den store fluktuasjonen i legebemanningen. Enn så lenge er bemanningen avhengig av om og når universitetene sender ut sine spesialistkandidater.

Totalt er det ca. 40 ansatte på selve sykehuset, hvorav fire har full sykepleierutdanning. I tillegg er det 18 ansatte i et omfattende landsbyhelsearbeid. Disse har utdanningsbakgrunn som helsearbeidere, med ekstrakurs i samfunnshelse. De er organisert $i$ en egen avdeling som sorterer under sykehusets ledelse. De arbeider utenfor sykehuset og har som sin viktigste oppgave å styrke og kvalitetssikre arbeidet som gjøres på de lokale helsestasjonene som myndighetene driver i distriktet.

\section{Medisinske assistenter}

En kategori ansatte som ikke er kjent i norsk sammenheng, er Community Medical Assistants (CMAs), dvs. medisinske assistenter. Her er fem slike, og de gjør mye av det som i Norge er legeoppgaver, selv om deres utdanning kun består av 18 måneder på helseskole etter tiende klasse. De undersøker de 28000 pasientene som årlig kommer til poliklinikken, behandler $80-90 \%$ av dem selv og henviser resten til lege. Én av dem står for mesteparten av vår anestesivirksomhet, en annen gjør ultralydundersøkelser, en tredje er tuberkuloseansvarlig, en fjerde har ansvaret for mor-barn-arbeid og tanntrekking (!), og den femte jobber med mental helse. Det overordnede medisinske ansvaret for disse funksjonene ligger hos overlegen, men de medisinske assistentene utfører mesteparten av det praktiske arbeidet.

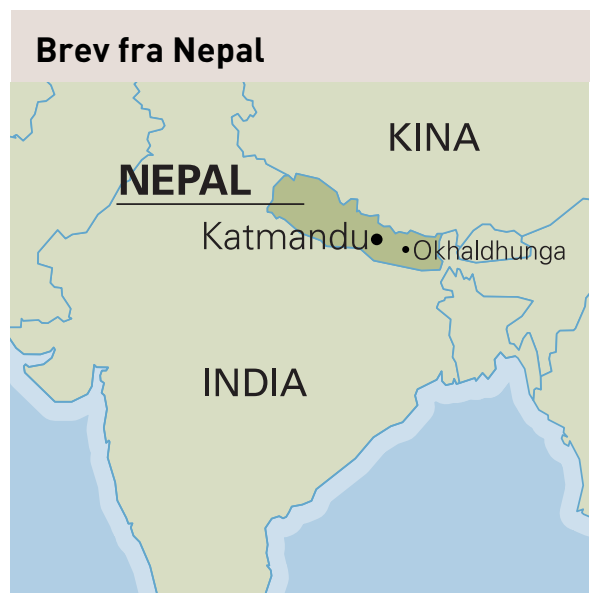

Det har vært betydelig motstand fra den nasjonale legeforeningen mot å gi ikkemedisinere opplæring $\mathrm{i}$ anestesi og ultralyd. Man mente det var uforsvarlig, selv om ikke noen anestesilege eller radiolog vil jobbe fast på utkantsykehus i Nepal. Slik stjal snevre laugsinteresser helsetjenester fra fattigfolk i utkanten. Etter at legeforeningen ga etter når det gjaldt anestesi for få år siden, gjør vi nå hver dag flere operasjoner i generell anestesi. Det å gi ikkemedisinere opplæring i bruk av ultralyd

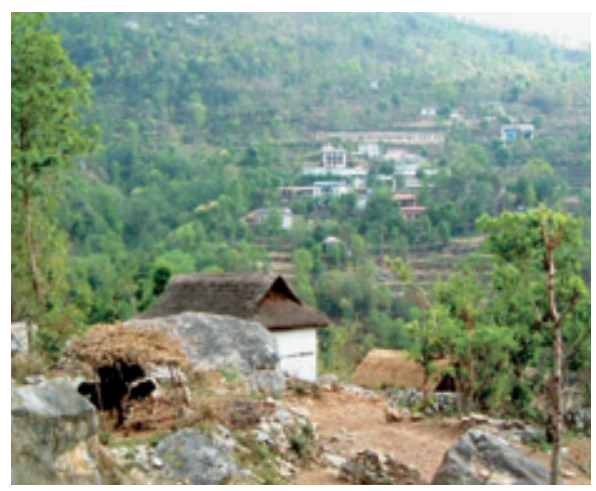

Figur 1 Sykehuset består av bygningene i husklyngen nær midten av bildet, og ligger i svært landlige omgivelser. Enkelt jordbruk er den dominerende næringsveien i distriktet. Begge foto Erik Bøhler 
møter fremdeles motstand. Vår ene medisinske assistent, som har fătt uformell opplæring, gjør 2500 ultralydundersøkelser $\mathrm{i}$ året, og det bidrar betydelig til sykehusets diagnostikk. Manglende opplæringstilbud til relevant stab gjør det vanskelig å konsolidere og videreutvikle denne tjenesten.

\section{Studietur}

Ledelsen ved sykehuset er jevnlig i kontakt med andre sykehus, men resten av staben får sjelden impulser utenfra. De ansattes fagforening foreslo at alle de sykehusansatte skulle dra på en ukes studietur. Men hvordan skulle hele staben kunne reise bort fra et sykehus med gjennomsnittlig over 500 pasientkonsultasjoner og 50 innleggelser i uken? Det er betydelig sesongvariasjon i arbeidsbelastningen her, så turen ble lagt til vinteren, da det er lavest aktivitet. Alle gruppene av stab (sykepleiere, poliklinikkarbeidere, rengjøringspersonale, administrasjonen, laboratorieansatte etc.) delte seg i to, slik at den ene halvparten kunne reise bort en uke mens den andre jobbet, og så vice versa to uker senere.

Vi besøkte seks ulike sykehus og samfunnshelseprosjekter. På alle stedene arrangerte vertskapet et orienteringsmøte og deretter en guidet tur på sykehuset. Der fikk hver gruppe av staben kontakt med sine egne kolleger og tid til å utveksle ideer med dem. Ikke minst rengjøringspersonalet benyttet denne sjansen aktivt. Rengjøring og avfallshåndtering er sentrale funksjoner på et sykehus, og personalet plukket opp tips om bruk av gulvbelegg og godtfungerende rengjøringsutstyr samt observerte gode og overførbare rutiner for avfallshåndtering i samarbeid mellom pasienter, pårørende og stab. Sykepleierne fikk en nyttig gjennomgang av rutiner for pleie av pasienter med akutte ryggskader med lammelser ved et spesialsykehus for slike skader. Basert på denne endret vi noe på behandlingsopplegget vårt for disse pasientene, som vi har mange av fordi fallskader er vanlig.

\section{Sykdomspanorama}

Pga. transportforholdene er det nesten ingen akutte tilstander som kan henvises herfra. Det er fem ukentlige flyavganger til Katmandu fra flyplassen som ligger fire timers gange fra sykehuset, men de blir ofte kansellert. Det betyr at akutte tilstander, fra akutt abdomen, obstetrikk, pediatri og kardiologi til hodeskader og utagerende psykoser, enten behandles her eller ikke blir behandlet i det hele tatt.

Stabile pasienter med tilstander som ikke krever umiddelbar behandling, kan henvises til store sykehus i Katmandu hvis de kan betale for seg der. Eksempler på slike tilstander er «kald» ortopedi og leppe-ganespalter.

Sykdomspanoramaet vi møter her synes bredere enn ved noen enkelt arbeidsplass i norsk helsevesen. Det omfatter også syk-

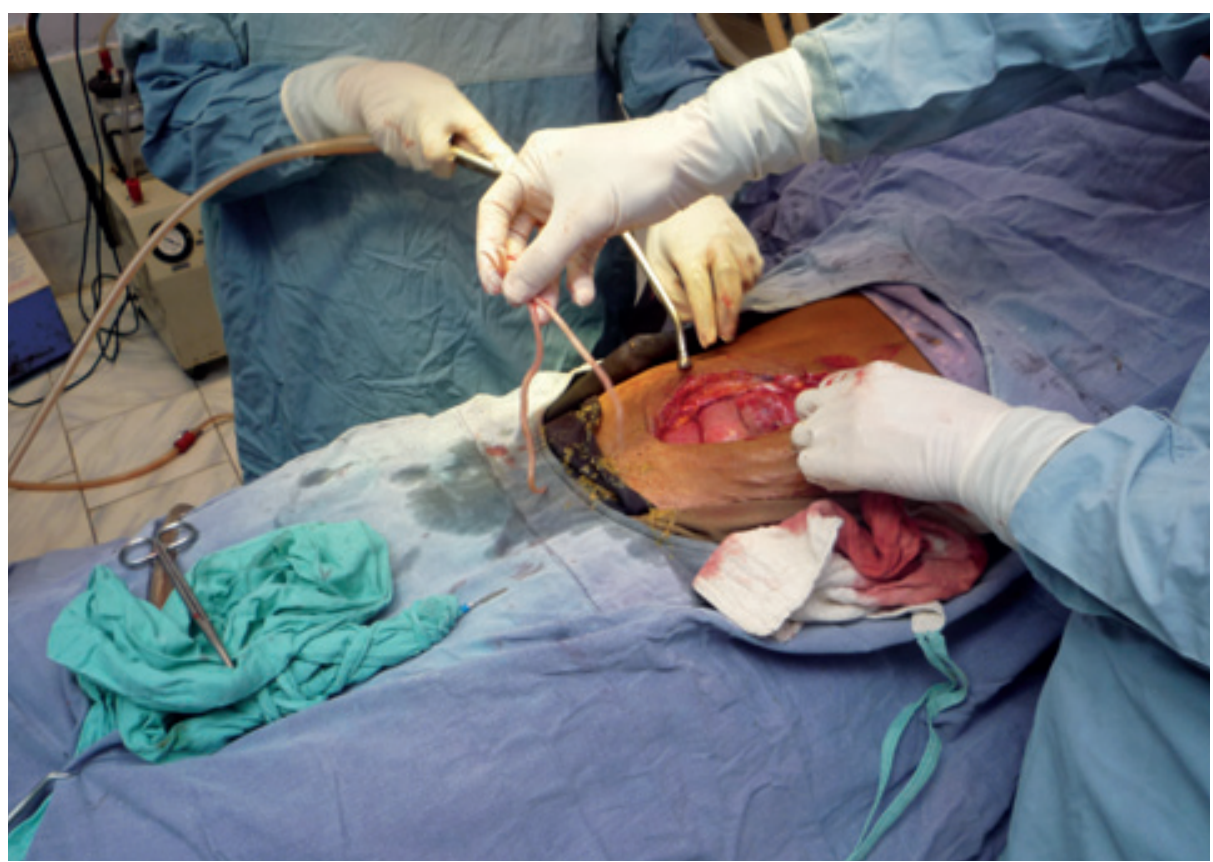

Figur 2 Avrevet tarm. Mange rundormer hadde rømt ut i bukhulen. Vi brukte mye av operasjonstiden til å lete etter rundormene. Her blir to av dem fisket opp

dommer vi aldri ser i Norge. Et eksempel er at vi ikke så sjelden får innlagt barn eller tenåringer med følgende kliniske bilde: De har hatt vekttap, slapphet og febrilia uten fokale symptomer i uker eller måneder. Ved undersøkelse har de hepatosplenomegali, og på vårt lille laboratorium finner vi anemi, lavt platetall og kanskje også lavt antall hvite blodlegemer og høy senkning. For en norsk pediater peker alt dette mot leukemi. Her er det nesten alltid feil. Disse barna har mye oftere kala azar, den viscerale formen for leishmaniasis. Diagnosen bekreftes ved funn av parasitter i milt og beinmarg, eventuelt ved hjelp av immunologisk analysesett. Inntil for et par års tid siden måtte vi behandle dem med daglige arsenikkinjeksjoner (natrium stibuglukonat) $i$ en måned. Utviklingen av effektive, sikre legemidler går langsomt for denne typen sykdommer, som alt overveiende rammer de fattiges barn. Nå har imidlertid indiske forskere utviklet og fătt registrert miltefosin, som er et tryggere og mer effektivt peroralt medikament mot kala azar (3).

Mange av sykdommene vi behandler er de samme som i Norge, men ofte arter de seg annerledes, fordi folk lever under andre forhold. Vi kan for eksempel få inn pasienter med tarmperforasjon som må laparotomeres, og der bildet kompliseres av at et antall rundormer har rømt fra sitt normale tilhold (under nepalesiske forhold) i tarmen, og ut i bukhulen (fig 2). En vesentlig del av kirugien blir da å finne og fjerne dem, fordi de ellers kan forårsake en farlig granulomatøs peritonitt (4) (fig 2).

I Nepal er omtrent halvparten av alle barn i skolealder undervektige (5). Både barn og voksne er gjennomsnittlig svært mye mindre enn i den rike verden, hvor mesteparten av forskning og medikamentutvikling foregår. Det er for tiden en økende bevissthet om behovet for justering av medikamentdoser til overvektige. I omgivelser som her er dosejusteringer for undervektige mer aktuelt. Det er antakelig minst like viktig, men foreløpig finnes det lite tilgjengelig kunnskap om dette (6).

\section{Gratis for småbarn og fødende}

Sykehuset får noe økonomisk støtte fra misjonsorganisasjoner i ulike land, og Norad gir betydelig støtte til landsbyhelsearbeidet. Mesteparten av driftsutgiftene til det kliniske arbeidet dekkes likevel av pasientenes egenbetaling. Alt, fra enkle blodprøver til kirurgiske operasjoner, betales etter et stykkprissystem. Det kan synes urimelig å ta betalt fra fattigfolk, men om man ikke gjorde det, ville sykehuset snart gå konkurs og måtte legges ned. Støtten som mottas fra landets egne myndigheter svarer til mindre enn $1 \%$ av driftsutgiftene. Heldigvis disponerer sykehuset et pasientstøttefond, som er bygd opp av gaver fra støttegrupper i flere land. Det brukes til å betale for helt nødvendig behandling for de aller fattigste, som ellers hadde måttet gå ubehandlet med livstruende sykdom. Fondet disponeres av sykehusets eget sosialkontor, basert på et vedtatt reglement med kriterier og regler for støtte.

For noen år siden hadde vi inntrykk av at det generelt var færre innleggelser av barn med diaré og pneumoni enn hva man skulle forvente epidemiologisk basert på tall fra Verdens helseorganisasjon (WHO) (7). Det så også ut til å være en skjev kjønnsfordeling, med mange flere gutter enn jenter innlagt.

Det var åpenbart at ordningen med pasientstøttefondet ikke fungerte etter intensjonen for småbarn. Fattigfolk kunne 
nok bringe sine sønner til sykehuset for behandling. Men ettersom de ikke kunne vite sikkert på forhånd at de ville få støtte til behandlingen, tok de ikke sjansen på å ta med sine syke døtre dit. Det anses som en dårlig investering å betale for behandling av jentebarn, de skal jo bare giftes bort likevel. Et nepalesisk ordtak beskriver hvor dumt det er å investere i døtres fremtid: «Det er som å vanne et tre i naboens hage».

Sykehusets styre bestemte derfor at all behandling av småbarn skulle være gratis. For å ha en enkel og objektiv grense sa man at dette skulle omfatte alle barn med vekt under $12 \mathrm{~kg}$. For denne gruppen skulle foreldrene kunne vite, før de kom til sykehuset, at behandlingen ville være gratis. De ansatte i landsbyhelsearbeidet og lokalradioen spredte kunnskap om nyordningen til befolkningen. Ved en opptelling året etter hadde antall barn under fem år økt med $56 \%$, og andelen jenter hadde økt til vel $40 \%(8,9)$.

Også fødende må betale for seg på sykehuset. En normal fødsel koster 1500 nepalske rupier. Det tilsvarer bare ca. 120 kroner, men i landsbyene er det ti dagslønner og altså en betydelig utgift. Totalprisen for en keisersnittpasient er minst åtte ganger så mye. Det er avskrekkende, selv om de fattigste får støtte fra pasientstøttefondet. I Nepal som helhet foregår $81 \%$ av alle fødsler uten trent fødselshjelper til stede (1), og det er grunn til å tro at tallet er enda høyere her i utkanten. Det er kjent at en ordning med stykkprisbetaling for helsetjenester reduserer befolkningens bruk av slike tjenester (10), og at denne effekten er større for kvinner enn for menn, og aller størst for barn $(11,12)$. I for eksempel Sierra Leone, som tidligere baserte hele sin helsetjeneste på direkte pasientbetaling, har et tilsvarende system hatt så negative konsekvenser for mødre og småbarn at det fra mars $2010 \mathrm{er}$ innført gratis helsetjenester for akkurat disse gruppene (13).

Det er derfor et stort fremskritt at fra neste budsjettår vil all fødselsomsorg på Okhaldhunga sykehus bli gratis. Det ble mulig etter at Nepals myndigheter gikk med på å dekke en vesentlig del av utgiftene ved fødsler. Resten av utgiftene vil bli dekket av utenlandske donorer. Dette vil gjøre det mulig å yte helt gratis fødselshjelp, så også de fattigste kan benytte seg av tilbudet. Videre er det et tegn på at landets myndigheter nå viser vilje til å ta ansvar for helsetjenester til sin egen befolkning, også de på landsbygda.

\section{Prioriteringsdebatt}

Ifølge WHO har Nepal en barnedødelighet på 59 per 1000 levendefødte barn og en mødredødelighet på 830 per 100000 fødsler. Tilsvarende tall for Norge er henholdsvis 4 per 1000 levendefødte barn og 7 per 100000 fødsler. Totale helseutgifter per innbygger i Nepal i 2007 var 20 dollar, mens tilsvarende tall for Norge var 7354 dollar (1). Nepal har mye større helseproblemer enn Norge, og landets helsevesen har forsvinnende små midler til rådighet for å møte dem. Likevel kan mye gjøres, og det er avgjørende at de begrensede midlene blir brukt riktig. I norske medier har det $\mathrm{i}$ år gått en debatt om prioriteringer i helsevesenet. Det er sunt, men perspektivet må være bredere enn bare vårt eget land. En økt prioritering av støtte til helsearbeid i fattige land, som Nepal, er påkrevd.
Oppgitte interessekonflikter: Ingen

\section{Litteratur}

1. World Health Statistics 2010. WHO: Genève, 2010. www.who.int/whosis/whostat/2010/en/index.html (23.9.2010)

2. Statistisk årbok 2009. Kapittel 2. Befolkning. Oslo: Statistisk sentralbyrå, 2009

3. Bhattacharya SK, Jha TK, Sundar S et al. Efficacy and tolerability of miltefosine for childhood visceral leishmaniasis in India. Clin Infect Dis 2004: 15 38: $217-21$

4. Chen D, Bo L. Ascaris peritonitis and peritoneal granuloma in China. J Gastroenterol 1997; 32: $826-9$.

5. Ghosh A, Adhikari P, Chowdhury SD et al. Prevalence of undernutrition in Nepalese children. Ann Hum Biol 2009; 36: 38-45.

6. Falagas ME, Karageorgopoulos DE. Adjustment of dosing of antimicrobial agents for bodyweight in adults. Lancet 2010; 375: 248-51.

7. WHO. The global burden of disease. 2004 Update (2008). Genève: World Health Organization, 2008.

8. Okhaldhunga Community Hospital. Annual Report 2005. Okhaldhunga: Okhaldhunga Community Hospital, 2005.

9. Okhaldhunga Community Hospital. Annual Report 2006. Okhaldhunga: Okhaldhunga Community Hospital, 2006.

10. Save the Children UK. An unnecessary evil? User fees for health care in low-income countries. London: Save the Children Fund, 2005.

11. Sauerborn R, Nougtara A, Latimer E. The elasticity of demand for health care in Burkina Faso: differences across age and income groups. Health Policy Plan 1994; 9: 185-92.

12. Gertler $P$, van der Gaag J. The willingness to pay for medical care: Evidence from two developing countries. Baltimore, MA: Johns Hopkins University Press, 1990.

13. Wakabi W. Mothers and infants to get free health care in Sierra Leone. Lancet 2010; 375: 882.

Manuskriptet ble mottatt 19.2. 2010 og godkjent 30.9. 2010. Medisinsk redaktør Mette Sagsveen. 